\title{
Analysis of Various Engine Parameters in Multicylinder Diesel Engines corresponding to Fuel Injection Timings
}

\author{
Nilesh B.Totala ${ }^{1}$, Rahul K. N. Singh ${ }^{2}$, Ankit Bansh ${ }^{3}$, \\ Mohd. Salman Mohd. Yaqub ${ }^{4}$, Rupesh Solanke ${ }^{5}$ \\ ${ }^{I}$ (Assistant Professor, Department of Mechanical Engineering,MIT Academy of Engineering,Alandi (D), Pune, \\ Maharashtra, 412105) \\ 2,3,4\&5 (Department of Mechanical Engineering, MIT Academy of Engineering, Alandi(D), Pune, \\ Maharashtra412105)
}

\begin{abstract}
The performance of diesel engine depends on fuel timings. Optimum fuel timing gives correct combustion of charge, less losses of charge, correct heat release pattern, reduced smoke level and NOx in exhaust. This leads to efficient performance of engine, reduced pollution hazards. Hence in this paper five tests on four cylinder diesel engines had been carried out at five different fuel timings. Each test is five mode tests and the effect of injection timing on various performance parameters is studied leading to conclusions.
\end{abstract}

Keywords: - Site specific fuel consumption, reference ambient conditions, Fuel injection, ISO 1878.

\author{
NOMENCLATURE \\ $\mathrm{P}_{\mathrm{x}}$-site power \\ $\mathrm{P}_{\mathrm{ra}}$-power at reference ambient conditions \\ $\alpha$-power adjustment factor \\ $\eta_{\mathrm{m}}$-mechanical efficiency \\ $\mathrm{T}_{\mathrm{x}}$-site temperature \\ $\mathrm{T}_{\mathrm{ra}}$-temperature at reference ambient conditions \\ $\mathrm{m}$-value of constant are taken from standards tables given in standard ISO 3046 \\ $\mathrm{n}$-value of constants are taken from standards tables given in standard ISO 3046 \\ $\beta$ - value taken from standard tables given in standard ISO 3046 \\ $\mathrm{SFC}_{\mathrm{ra}}$-specific fuel consumption at reference ambient condition
}

\section{INTRODUCTION}

It is known that for good performance of diesel engine $\mathrm{A} / \mathrm{F}$ ratio should be large, fuelling should be less, NOx should be least, specific fuel consumption should be less. Performance of diesel engine depends upon the crank angle at which diesel is injected in engine cylinder. There are particular crank angles at which diesel should be injected in the engine cylinder. This is dependent on the parameters which are selected. These can be air fuel ratio, fuelling, SFC, exhaust temperature, airflow, NOx. In this paper, experimentation tests on diesel engine are carried out. Here r.p.m. of engine, torque at engine shaft, power developed at engine shaft, time required for $560 \mathrm{ml}$ fuel, SFC, NOx etc. are measured. Jonas Asprionet.al[1] combined empirical and phenomenological models of nitrogen oxide emissions of Diesel engines taking into account engine speed, injected fuel mass, cylinder charge its composition. H.E.Saleh[2]showed that by exhaust gas recirculation is an effective technique for reducing NOx emissions with jojoba methyl ester fuel in light duty diesel engines. IsmetSezer[3] compared the diesel engine performance i.e. brake power, brake specific fuel consumption, brake thermal efficiency for diesel fuel, dimethyl ether and diethyl ether. And concluded that for same injection conditions performance deteriorates for dimethyl ether and diethyl ether, whereas the performance enhances for dimethyl ether and diethyl ether for same equivalence ratio. L. Tartakovsky[4]showed that oil additizing by the Motorsilk oil additive leads to a reduction of specific fuel consumption in the whole tested range of operation regimes by $2-7 \%$ compared to the reference case.Further fuel additizing by LubriSilk additive resulted in fuel economy improvement compared to the reference case: of $5-10 \%$ at $1500 \mathrm{rpm}$ and $3-5 \%$ at 2300 r.p.m. The test results show some tendency of reduction of NOx concentrations in the exhaust gases with fuel additizing by LubriSilk additive. The most pronounced reduction of NOx emissions was achieved after 30 hours of engine running-in with Additized fuel: $13-30 \%$ at engine speed of $1500 \mathrm{rpm}$ and $4-15 \%$ at engine speed of 2300 $\mathrm{rpm}$. Oil additizing does not lead to any significant change in NOx emissions of the tested engine. Avinash Kumar et.al [5], showed that at fixed power conditions, as the percentage EGR increases $(0-21 \%)$, the temperature of the exhaust gas continuously decreases. Earlier it was mentioned that the most important reason for the formation of NOx in the combustion chamber is extremely high temperature. Their experimental results 
indicate a decrease in the exhaust temperatures with increasing EGR, therefore it can be safely concluded that the combustion chamber temperatures also decrease and thus the formation of NOx is decreased. This reduction in exhaust gas temperature does not affect the thermal efficiency. Thermal efficiency remains unaffected by EGR, Capacity of the exhaust gas increases as the rate of EGR is increased. At low loads, the rate of increase in capacity is almost the same with increase in EGR but at higher loads and higher rates of EGR, capacity increases rapidly, as Further it was also found that the brake specific fuel consumption (BSFC) is fairly independent of EGR As load increases, BSFC decreases rapidly. Five mode tests on engine are done as per manual of test benches.Measurement of power, fuel and lubricating oil consumption is done according to international standard ISO 3046.Measurement of exhaust gases i.e. smoke $\& \mathrm{NO}_{\mathbf{x}}$ is done according to international standard ISO 8178 calibration of all instruments used for measurement of various experimental parameters are calibrated in standard room prior to laboratory utilization.

\section{METHODOLOGY AND EXPERIMENTATION}

This involves preparing the engine for testing. The engine is assembled with all required parts i.e. Turbocharger, radiator, dynamometer, fuel injection pump etc.

Five mode tests consist of testing the engine at five different load conditions at constant speed at $100 \%$ load, $75 \%$ load, $50 \%$ load, $25 \%$ load and 10\% load. Engine is fitted with fuel injection pump for setting at $7 \mathrm{deg}$. before top dead center position. For this setting first five mode test at constant $1500 \mathrm{rpm}$ is conducted. This five mode tests consist of measurement of power, fuel and lubricating oil consumption. Also it consists of measurement of exhaust emissions i.e. smoke $\& \mathrm{NO}_{\mathrm{x}}$.

According to ISO 3046 power produced by the engine at site conditions should be corrected to NTP(Normal Temperature Pressure) conditions. For turbocharged engine power correction formulas are;

$\mathrm{P}_{\mathrm{x}}=\alpha \times \mathrm{P}_{\mathrm{r}}$

Where $\mathrm{P}_{\mathrm{x}}$ is the site power and $\mathrm{P}_{\mathrm{ra}}$ is the power at reference ambient conditions.

The power adjustment factor $\alpha$ is given by,

$\alpha=\mathrm{k}-0.7(1-\mathrm{k})\left(1 / \eta_{\mathrm{m}}-1\right)$

$\eta_{\mathrm{m}^{-}}$mechanical efficiency

Where $\mathrm{k}$ is given by,

$\mathrm{k}=\left(\mathrm{P}_{\mathrm{x}} / \mathrm{P}_{\mathrm{ra}}\right)^{\mathrm{m}}\left(\mathrm{T}_{\mathrm{ra}} / \mathrm{T}_{\mathrm{x}}\right)^{\mathrm{n}}$

$\mathrm{T}_{\mathrm{x}}$ and $\mathrm{T}_{\mathrm{ra}}$ is the site temperature and temperature at reference ambient conditions respectively.

Value of constants $\mathrm{m}$ and $\mathrm{n}$ are taken from standards tables given in standard ISO 3046.

According to ISO 3046 specific fuel consumption is given as,

Site $\mathrm{SFC}=\beta \times \mathrm{SFC}_{\mathrm{ra}}$

$\beta$ - Value taken from standard tables given in standard ISO 3046

$\mathrm{SFC}_{\mathrm{ra}}$-specific fuel consumption at reference ambient condition.

The exhaust emission analysis i.e. NOx, particulate emission smoke is done by ISO 8178.Engine test condition, test validity, engine air inlet system, engine exhaust system i.e. necessary back pressure in exhaust system, engine cooling system i.e. normal operating system in engine cooling system are decided by ISO 8178. Measurement equipment and data to be measured, exhaust gas flow measurement, determination of gaseous components like $\mathrm{CO}, \mathrm{CO}_{2}, \mathrm{O}_{2}, \mathrm{HC}, \mathrm{SO}_{2}$, and $\mathrm{NH}_{3}$ etc. are also decided according to ISO 8178.It also decides determination of particulate emissions by means of filters, calibration of analytical instruments, corrections to weight/ dry measurements, applications of corrections for particulate emissions, measurement of specific emissions, methods of exhaust gas flow measurements such as carbon balance method, carbon/ oxygen balance method.

Here 12 different parameters are noted for each mode.

a) Engine speed (r.p.m)

b) Observed engine torque $(\mathrm{Nm})$

c) Time required for $560 \mathrm{ml}$ of fuel $(\mathrm{sec})$

d) NOx (ppm) 
e) Exhaust smoke level $\left(\mathrm{m}^{-1}\right)$

f) Temperature after and before exhaust gas turbine $\left({ }^{\circ} \mathrm{C}\right)$

g) Pressure after and before exhaust gas turbine $\left(\mathrm{mm}\right.$ of $\left.\mathrm{H}_{2} \mathrm{O}\right)$

h) Pressure, temperature before and after air compressor. $\left(\mathrm{kg} / \mathrm{cm}^{2},{ }^{\circ} \mathrm{C}\right.$ respectively)

i) Air flow rate $(\mathrm{kg} / \mathrm{min})$

j) Lubricant oil temp $\left({ }^{\circ} \mathrm{C}\right)$

k) Lubricant oil pressure $\left(\mathrm{kg} / \mathrm{cm}^{2}\right)$

1) Coolant temperature $\left({ }^{\circ} \mathrm{C}\right)$

After noting all these parameters, power output is calculated from torque and speed in KW. Air fuel ratio, compressor efficiency are calculated for all the readings. Now the engine is assembled at $9 \mathrm{deg}, 11 \mathrm{deg}, 13$ deg, and 15deg. BTDC (before top dead center) setting of fuel pump. And the five mode tests are carried out for all these fuel pump settings. All the required engine parameters are noted and calculations are made. Detail readings of above mentioned parameters are taken. Afterwards calculations for following parameters are made viz; SFC ( $\mathrm{kg} / \mathrm{KW}-\mathrm{hr})$, fuelling $\left(\mathrm{mm}^{3} / \mathrm{min}\right)$, and A/F ratio. Graphs of these parameters along with NOx, Exhaust temperature $\left({ }^{\circ} \mathrm{C}\right)$, air flow $(\mathrm{kg} / \mathrm{min}) \mathrm{v} / \mathrm{s}$ load are plotted at all five loads viz; $10 \%, 25 \%, 50 \%, 75 \%$ and $100 \%$ for all five fuel pump settings. Load is in Nm. Pump settings are taken at separate fuel injection timings in rank angles of before T.D.C.(BTDC).

\section{RESULTS AND DISCUSSIONS}

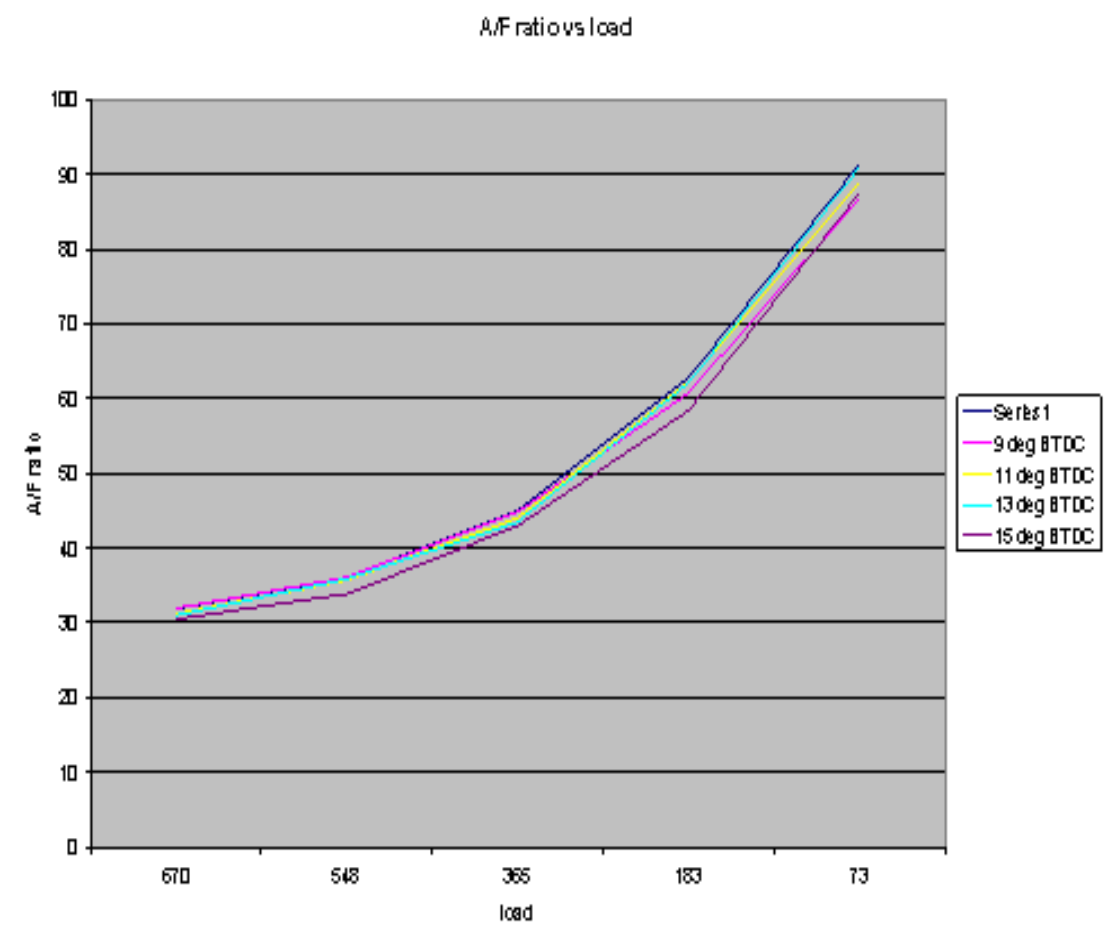

Fig1.Variation of Air fuel ratio v/s load for different fuel injection timings. 
fuelling us load

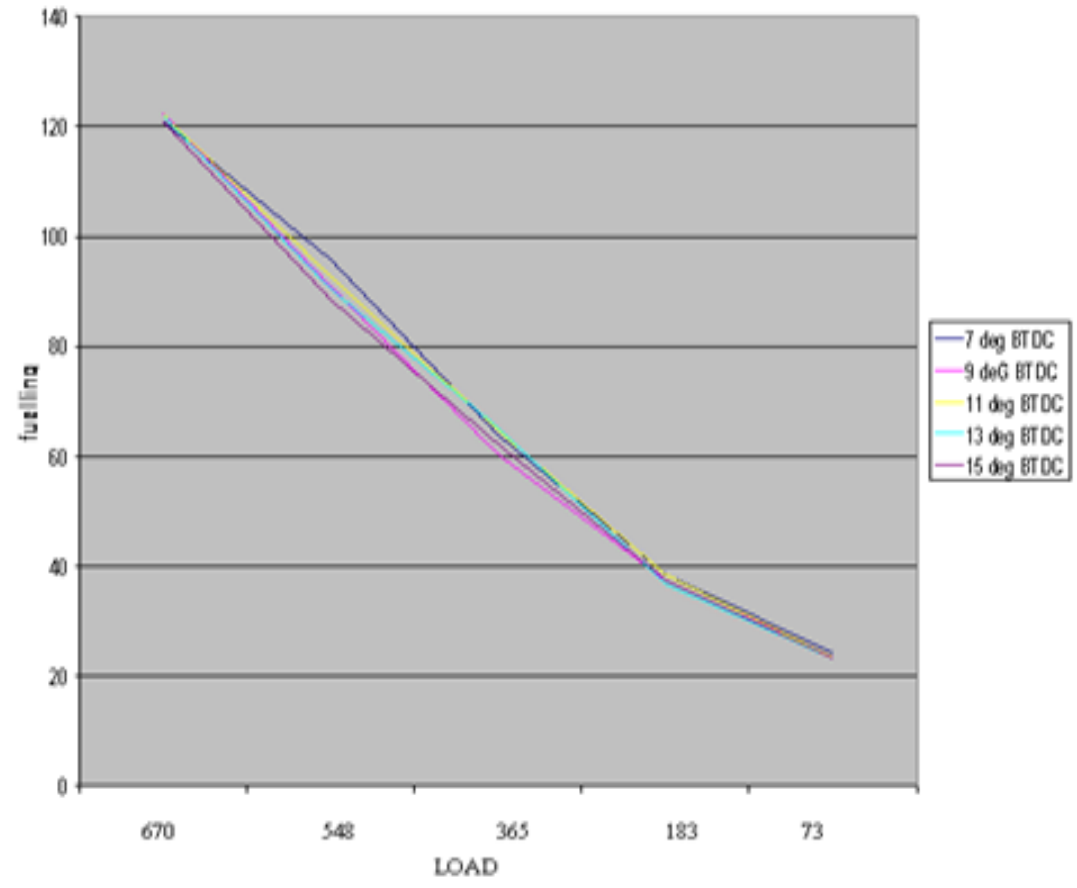

Fig: 2. Variation of fuelling v/s load for different fuel injection timings.

NOE vs load

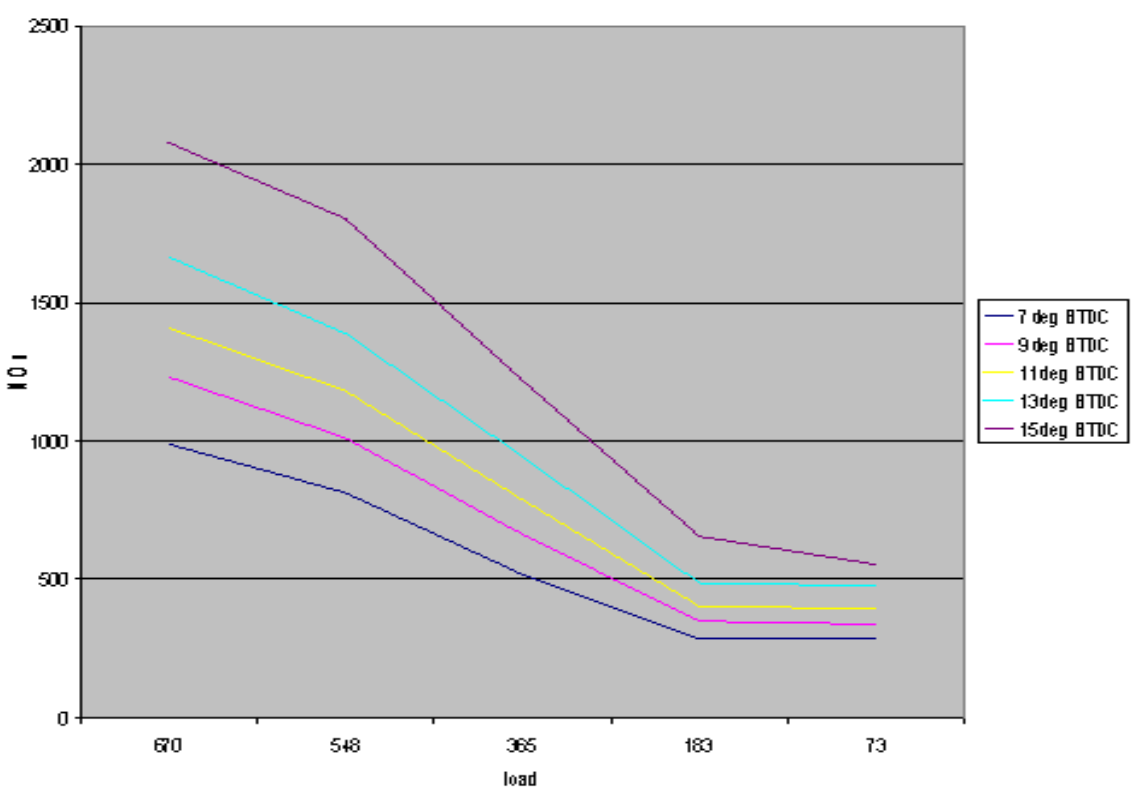

Fig.3.Variation of NOx v/s load for different fuel injection timings. 
sfc us load

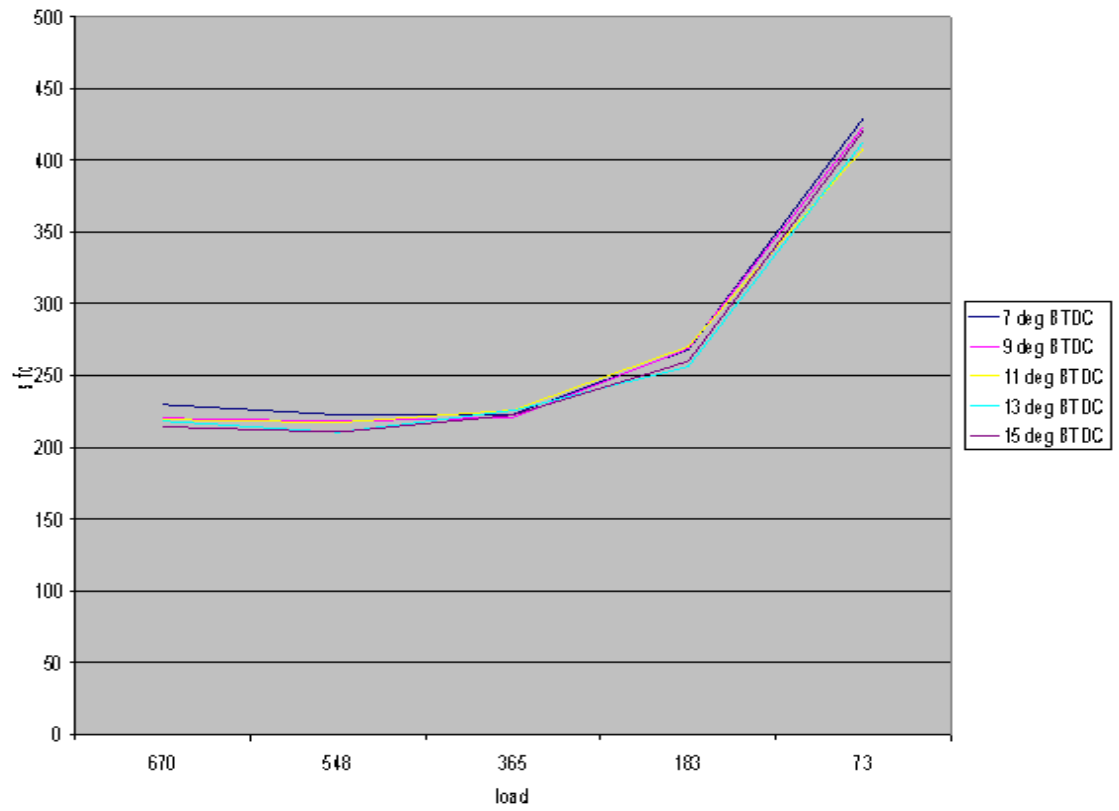

Fig:4.Variation of SFC v/s load for different fuel injection timing

Exhaust temp. is load

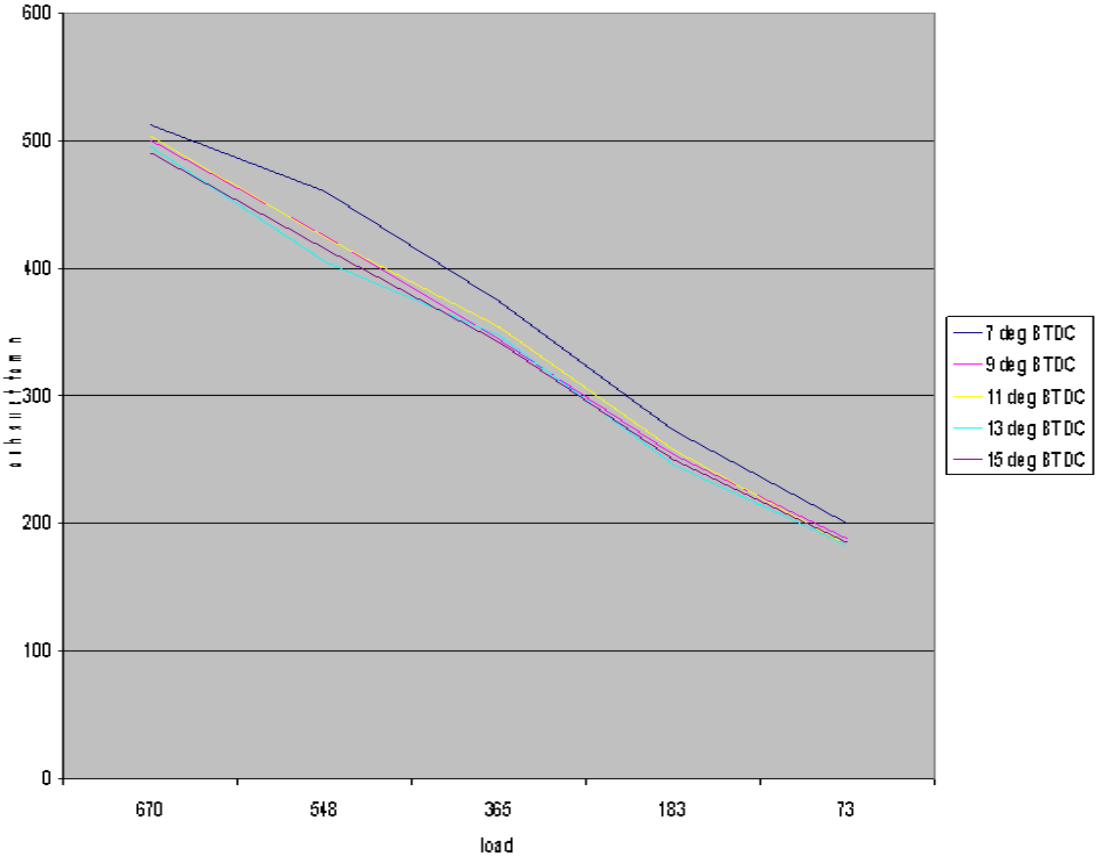

Fig.5. Variation of Exhaust temperature v/s load for different fuel injection timings. 


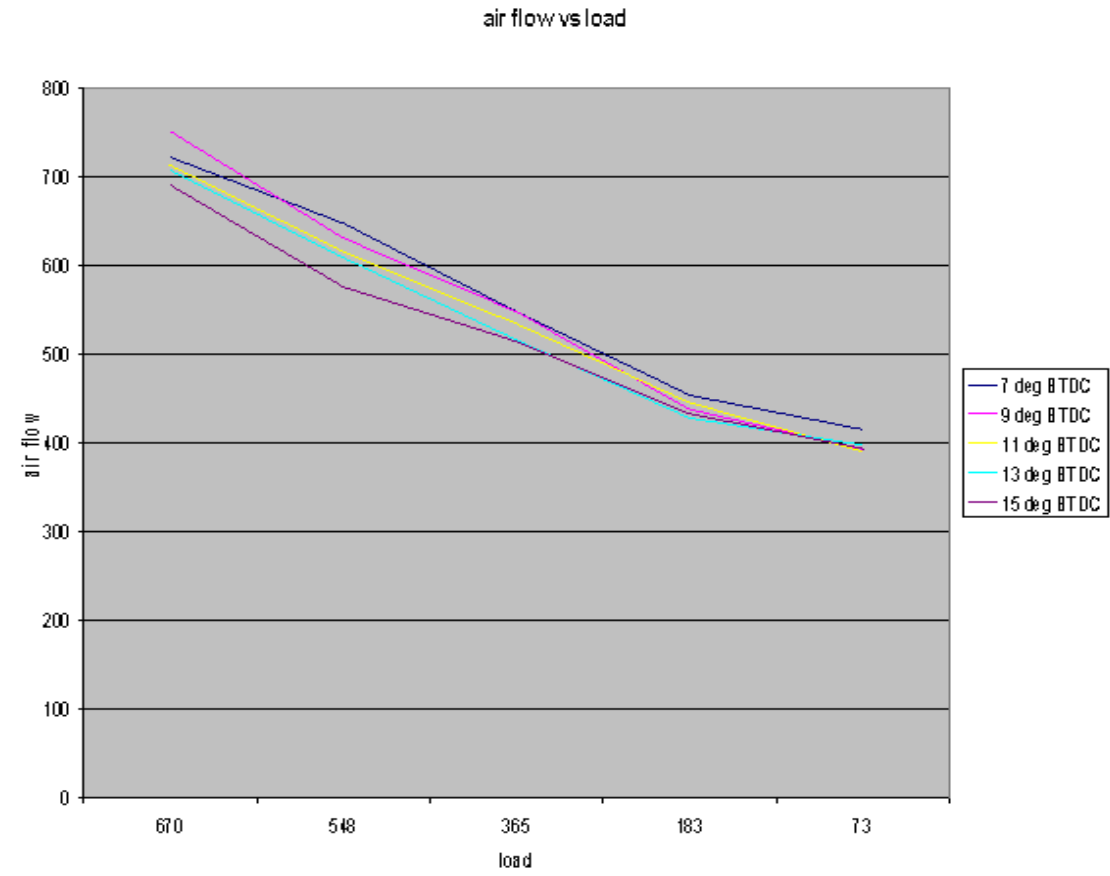

Fig. 6: Variation of Airflow v/s load for different fuel injection timings.

\section{DISCUSSIONS}

3.1 AIR FUEL RATIO $V / S$ LOAD.

i. As load decreases A/F ratio increases which is true for any type of fuel pump setting that is $7 \mathrm{deg}$; 9 deg;11deg; 13deg and15deg.BTDC. There is very sharp rise in A/F ratio.

ii. $\quad$ As advance of the fuel timing increases i.e. from $7 \mathrm{deg}$; to15deg.the $\mathrm{A} / \mathrm{F}$ ratio goes on decreasing.

iii. For one load $\mathrm{A} / \mathrm{F}$ ratio increases as advance is decreased i.e. charge gets more diluted as advance is decreased along with load.

\subsection{FUELLING $V / S$ LOAD}

i. As load reduces fuelling reduces i.e. fuel taken up by the cylinder per stroke reduces.

ii. Advance is increased fuelling reduces.

iii. For a given load condition fuelling does not vary much with advance, so the trend is similar for all with respect to fuelling vs. load.

\subsection{NOx V/S LOAD}

i. As load reduces NOx reduces i.e. NOx is directly proportional to applied load for all types of fuel settings.

ii. As advance increases for a given load NOx increases which is as shown in the graph.

iii. There is a huge difference between the values of NOx for given load for different values of fuel settings.

\subsection{SFC V/S LOAD}

i. As load decreases, $\mathrm{SFC}$ increases

ii. The increase of SFC is very sharp from $25 \%$ load to $10 \%$ load.It is nearly constant for $100 \%$ load to $50 \%$ load and the variation is slightly more from $50 \%$ load to $25 \%$ load.

iii. SFC vs. load does not vary much with respect to fuel pump advance or we can write as fuel pump advance is increased SFC is reduced for a given load condition by small amount.

\subsection{EXHAUSTTEMPERATURE $V / S$ LOAD}

i. As load decreases, exhaust temperature decreases i.e. load is directly proportional to exhaust temperature.

ii. As fuel pump advance is increased exhaust temperature reduces for a given load so there is inverse relationship between fuel pump advance and exhaust temperature.

iii. There is very sharp decrease in exhaust temperature with respect to load reduction. 


\subsection{AIRFLOW V/S LOAD}

i. $\quad$ As load reduces airflow also reduces.

ii. For a given load, airflow reduces with advance.

iii. The trend is somewhat irregular at some point with fuel advance airflow increases, at some points it reduces.

\subsection{A/F RATIO $V / s$ LOAD}

\section{CONCLUSION}

i. As load increases, to meet the demand more fuel is required and hence $\mathrm{A} / \mathrm{F}$ ratio decreases with an increase in load.

ii. As the fuel injection timing is advanced $\mathrm{A} / \mathrm{F}$ ratio increases as the time available for efficient combustion of charge reduces. This is in accordance with the reduction of bypassing of unburnt fuel in exhaust.

\subsection{FUELLING $V / s$ LOAD}

i. As the load reduces , fuelling also reduces in accordance with the demand. This is similar to the conclusion drawn for the preceding section above.

\section{3 $\mathrm{NO}_{\mathrm{x}} \mathrm{V} / \mathrm{s}$ LOAD}

i. As the load is increased, fuelling increases .This leads to an increase in the average temperature and pressure inside the combustion chamberhence $\mathrm{NO}_{\mathrm{x}}$ increases.

ii. As the fuel injection timing is advanced for a particular load more $\mathrm{NO}_{\mathrm{x}}$ is produced as fuelling is given leading to increased combustion temperatures and pressures thereby increasing the quantity of $\mathrm{NO}_{\mathrm{x}}$

\subsection{SFC V/S LOAD}

i. As the load increases, the denominator (Power) in the expression for SFC increases. The effect of increase in power over increase in fuelling is predominant leading to a decrease in SFC.

\subsection{EXHAUST TEMPERATURE $V / S$ LOAD}

i. As the load is increased, fuelling increases resulting in increased average temperatures leading to an increase in the average exhaust temperatures.

ii. This trend is also true for injection timings. As the timings are advanced the exhaust gas temperatures increase.

\subsection{AIRFLOW V/S LOAD}

i. As the load increases, in order to have efficient combustion of chargemore air is taken resulting in more airflow.

\section{REFERENCES}

[1] Jonas Asprion, Oscar Chinellato, LinoGuzzella,A fast and accurate physics-based model for the NOx emissions of Diesel engines,2013, Journal of applied energy, Elsevier, pp 221-23.

[2] H.E.Saleh, Effect of exhaust gas recirculationon diesel engine nitrogen oxide reduction operating with jojoba methyl ester,2009,journal of Renewable Energy,pp 2178-2186.

[3] IsmetSezer, Thermodynamic, performance and emission investigation of a diesel engine running on dimethyl ether and diethyl ether, 2011, International journal of Thermal Sciences 50, pp1594-1603.

[4] L. Tartakovsky, M. Veinblat, V. Baybikov, M. Gutman, and Y. Zvirin,EffectsofMotorsilkOil and Fuel Additives on Fuel Consumption and Emissions of Diesel Engine,2006,Logus Ltd.

[5] AvinashkumarAgrawal, Shrawan Kumar Singh, ShailendraSinha, Mrityunjay Kumar Shukla, Effect of EGR on the exhaust gas temperature and exhaust capacity in compression ignition engines ,June 2004,Sadhana Vol. 29, Part 3, pp. 275-284.

[6] Manual of test benches. 